\title{
Polymalic Acid Tritryptophan Copolymer Interacts with Lipid Membrane Resulting in Membrane Solubilization
}

\author{
Hui Ding, ${ }^{1}$ Irving Fox, ${ }^{1}$ Rameshwar Patil, ${ }^{1}$ Anna Galstyan, ${ }^{1}$ Keith L. Black, ${ }^{1}$ \\ Julia Y. Ljubimova, ${ }^{1}$ and Eggehard Holler ${ }^{1,2}$ \\ ${ }^{1}$ Department of Neurosurgery, Cedars-Sinai Medical Center, Los Angeles, CA 90048, USA \\ ${ }^{2}$ Institut für Biophysik und Physikalische Biochemie der Universität Regensburg, Regensburg, Germany \\ Correspondence should be addressed to Hui Ding; hui.ding@cshs.org
}

Received 19 January 2017; Revised 27 March 2017; Accepted 16 April 2017; Published 21 May 2017

Academic Editor: Abdelwahab Omri

Copyright (C) 2017 Hui Ding et al. This is an open access article distributed under the Creative Commons Attribution License, which permits unrestricted use, distribution, and reproduction in any medium, provided the original work is properly cited.

\begin{abstract}
Anionic polymers with membrane permeation functionalities are highly desirable for secure cytoplasmic drug delivery. We have developed tritryptophan containing copolymer (P/WWW) of polymalic acid (PMLA) that permeates membranes by a mechanism different from previously described PMLA copolymers of trileucine (P/LLL) and leucine ethyl ester (P/LOEt) that use the "barrel stave" and "carpet" mechanism, respectively. The novel mechanism leads to solubilization of membranes by forming copolymer "belts" around planar membrane "packages." The formation of such packages is supported by results obtained from studies including size-exclusion chromatography, confocal microscopy, and fluorescence energy transfer. According to this "belt" mechanism, it is hypothesized that P/WWW first attaches to the membrane surface. Subsequently the hydrophobic tryptophan side chains translocate into the periphery and insert into the lipid bilayer thereby cutting the membrane into packages. The reaction is driven by the high affinity between the tryptophan residues and lipid side chains resulting in a stable configuration. The formation of the membrane packages requires physical agitation suggesting that the success of the translocation depends on the fluidity of the membrane. It is emphasized that the "belt" mechanism could specifically function in the recognition of abnormal cells with high membrane fluidity and in response to hyperthermia.
\end{abstract}

\section{Introduction}

Delivery of drugs through membrane barriers is an issue in modern nanomedicine comparably important with high water solubility, biodegradability, absence of toxicity, and immunogenicity. A polymeric nanoplatform meeting these requirements and with excellent ability to deliver a multitude of different drugs and/or imaging agents is polymalic acid (PMLA) [1]. Its chemical polyfunctionality enables not only delivery of drugs and imaging agents but also the conjugation of functional groups which can interact with biological membranes and influence cellular uptake, subcellular compartmentation, cell viability, and last but not least the efficiency of drug delivery $[2,3]$. The understanding of the interaction of a polymer platform and its covalent payload regarding permeation of membrane barriers is thus highly desirable. For instance, amphiphilic polyanions functioning in membrane permeation have been proven valuable for cytoplasmic delivery of nucleic acid based and small molecular therapeutics [4-7].

We have explored poly( $\beta$-L-malic acid) (PMLA) as the molecular platform to deliver antisense oligonucleotides [8$10]$, chemotherapeutic drugs [11, 12], and cancer imaging agents [13]. When conjugated with certain hydrophobic amino acids, the natural hydrophilicity of PMLA was controlled and tuned to become lipophilic for cytoplasmic delivery through endosomal membranes [14]. Lipophilization involved amide-conjugation of the oligopeptides trileucine (LLL) or tritryptophan (WWW) and also leucine ethyl ester (LOEt). The substituted PMLA acquired the properties for $\mathrm{pH}$-responsive and constitutive permeation of lipid membranes [14]. These membrane permeating activities depending on the nature of the amino acid side chain were identified using an in vitro liposome leakage assay. The 
leakage inducible mode of interaction between polymer and membrane was best described for PMLA/LLL to follow the "barrel stave" mechanism and for PMLA/LOEt the "carpet" mechanism [15]. The mechanism for PMLA/WWW did not follow either of these mechanisms, and experimental evidences are presented here together with a view of the mechanism.

Typically the "carpet" and "barrel stave" mechanisms [16] involve a primary complex of the polymer with the membrane at the membrane surface. However, in the case of $\mathrm{P} / \mathrm{LLL}$, several molecules of the polymer interact to form a barrel-like structure that insert into the core of the lipid membrane $[15,17,18]$, while in the "carpet" model P/LOEt molecules approach the membrane and align with head groups of phospholipids at the surface with the LOEt groups inserting into the membrane $[15,17,18]$. The third possible mode of interaction with membrane has been proposed to involve "belt formation." This mode has rarely been applied for describing a polymer-membrane interaction. It has been proposed to describe membrane protein complexes in the form of nanodiscs generated by high-density lipoprotein (HDL) [19-21]. In the "belt formation" model, two or more apolipoprotein molecules A-I (apoA-I) arrange like a belt around alkyl chains of the lipid bilayer resulting in a discoidal structure [22]. For the purpose of stabilizing membrane homed protein lipid interactions, amphipathic polymers have been reported to form small packages consisting of lipids and membrane proteins [23]. In this context, functional membrane protein has been encapsulated by styrene maleic acid (SMA) copolymer directly from the membrane into a nanoscale lipid particle [24]. While these studies report on the copolymer-assisted isolation of membrane standing proteins into small lipid entities, our contribution reports on the packaging of membranes in the absence of proteins.

We studied the mode of action of membrane permeation and solubilization by $\mathrm{P} / \mathrm{WWW}$ using model lipid membranes such as liposome and giant unilamellar vesicle. Various techniques were used to probe the interaction between lipid and P/WWW including size-exclusion HPLC (SE-HPLC) confocal microscopy, fluorescence resonance energy transfer (FRET), and transmission electron microscopy (TEM). The experimental results will be examined in the light of the three mechanisms, "barrel stave," "carpet," or "belt formation."

\section{Materials and Methods}

2.1. Materials. Poly( $\beta$-L-malic acid) (PMLA) ( $75 \mathrm{kDa}$; polydispersity 1.3) was obtained from culture broth of Physarum polycephalum as described $[1,25]$. Tritryptophan H-Trp-TrpTrp-OH (WWW), trileucine H-Leu-Leu-Leu-OH (LLL), and H-Leu-OEt (LOEt) were purchased from Bachem Americas Inc. (Torrance, CA, USA). Rhodamine Red C2 maleimide (Rh) was purchased from Invitrogen (Carlsbad, CA, USA). Egg PC (L- $\alpha$-phosphatidylcholine) and 1,2-dioleoyl-snglycero-3-phosphoethanolamine-N-(7-nitro-2-1,3-benzoxadiazol-4-yl) (NBD-PE) were purchased from Avanti Polar Lipids (Alabaster, AL, USA). Cholesterol was from SigmaAldrich (St. Louis, MO, USA).
2.2. Synthesis of $P / W W W$ and P/LOEt. PMLA copolymers $\mathrm{P} / \mathrm{WWW}$ and P/LOEt (for structures, see Figure 1) have been synthesized based on the method previously described $[8,14]$. Briefly, to a $0.2 \mathrm{~mL}$ solution of PMLA (25 mg, $0.22 \mathrm{mmol}$ equivalent of malic acid) in acetone was added a mixture of $N$-hydroxysuccinimide (NHS, $25 \mathrm{mg}, 0.22 \mathrm{mmol}$ ) and dicyclohexylcarbodiimide (DCC, $47 \mathrm{mg}, 0.22 \mathrm{mmol}$ ) in $0.2 \mathrm{~mL}$ DMF. After $2 \mathrm{hr}$ stirring at room temperature, $\mathrm{H}$ Trp-Trp-Trp-OH (50 mg, $0.088 \mathrm{mmol}, 40 \%$ equivalent to the total malyl groups) dissolved in DMF. The completion of conjugation was verified by TLC (ninhydrin test). Unreacted $N$-hydroxysuccinimidyl ester was hydrolysed by the addition of $1 \mathrm{~mL}$ phosphate buffer (100 mM pH 6.8). The dicyclohexylurea precipitate was removed by filtration. The product $\mathrm{P} / \mathrm{WWW}$ was purified over PD-10 column to remove organic solvent and residual small molecules (GE Healthcare). P/LOEt was prepared similarly.

\subsection{Synthesis of Fluorescent Rhodamine Labeled $P / W W W / R h$} and $P / L O E t / R h$. To prepare $\mathrm{P} / \mathrm{WWW} / \mathrm{MEA}$, the remaining unreacted $\mathrm{N}$-hydroxysuccinimidyl ester was used for conjugation of 2-mercaptoethylamine hydrochloride (MEA, $1.6 \mathrm{mg}, 0.012 \mathrm{mmol}, 2 \%$ equivalent to the total malyl groups) in the presence of triethylamine $(2.4 \mu \mathrm{L})$. Reaction completion after $30 \mathrm{~min}$ was tested on TLC with ninhydrin. Remaining unreacted $\mathrm{N}$-hydroxysuccinimidyl ester was hydrolysed by the addition of phosphate buffer $\mathrm{pH}$ 6.8. The product $\mathrm{P} / \mathrm{WWW} / \mathrm{MEA}$ was purified over PD-10 column (GE Healthcare). P/LOEt/MEA was prepared similarly.

Rhodamine Labeled Copolymers P/WWW/Rh and P/LOEt/ $R h$. To the solution of P/WWW/MEA or P/LOEt/MEA (1.7 mg each) in phosphate buffer $(100 \mathrm{mM} \mathrm{pH} \mathrm{6.3)} \mathrm{was}$ added rhodamine Red C2 maleimide (1\% equivalent to total malyl group) dissolved in DMF. The reaction was kept dark at room temperature with shaking for 2 hours. Unreacted thiols on polymer were blocked with excess of 3-(2-pyridyldithio)-propionate (PDP) at room temperature. The product $\mathrm{P} / \mathrm{WWW} / \mathrm{Rh}$ was purified over PD-10 column.

\subsection{Solubilization of Multilamellar Vesicles by $P / W W W$. Egg} PC $5 \mathrm{mg}$ and cholesterol $1.25 \mathrm{mg}$ were dissolved in $0.5 \mathrm{~mL}$ chloroform and $0.25 \mathrm{~mL}$ methanol in each of four glass vials. The solvent was removed by $\mathrm{N}_{2}$ stream to form a thin film on the wall of the vial. Residual solvent was removed by vacuum evaporation for $2 \mathrm{~h}$ at room temperature. PBS $1 \mathrm{~mL}$ was added to the lipid film which was suspended by vortexing and shaking for $30 \mathrm{~min}$. The suspension contained multilamellar vesicles (MLV) as visualized by microscopy. Mixtures containing the MLV suspension and P/LOEt, PWWW, P/LLL $0.5 \mathrm{~mL}(5 \mathrm{mg} / \mathrm{mL})$, or PBS $0.5 \mathrm{~mL}$ were prepared in different vials. The final concentrations for lipid and polymers were $3.3 \mathrm{mg} / \mathrm{mL}$ and $1.7 \mathrm{mg} / \mathrm{mL}$, respectively. After three times of shaking for $30 \mathrm{~min}$, sonication for $10 \mathrm{~min}$ at room temperature, and standing at $4^{\circ} \mathrm{C}$ overnight, the transparency was checked visually. Each suspension was then centrifuged, filtered through a $0.2 \mu \mathrm{m}$ membrane filter before the hydrodynamic diameter of particles in the filtrate was measured by Zeta-sizer Nano-ZS90 (Malvern Instruments, UK). 
<smiles>[R]C(=O)C(CC(=O)OC(CC(=O)O)C(=O)O)OC([3H])C</smiles>

PMLA: $\mathrm{R}=\mathrm{H}$<smiles>CCCNC(CC(C)C)C(=O)OCC</smiles>

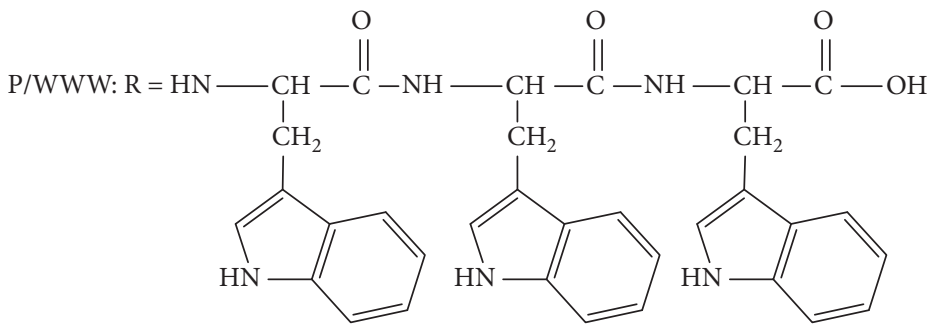<smiles>[R11]C(C)CCC(NC(=O)C(CC(C)C)NC(=O)C(CC(C)C)NC(=O)O)C(C)C</smiles>

Figure 1: Structure of polymalic acid and polymalic acid copolymers P/LOEt, P/WWW, and P/LLL which are grafted with either $40 \%$ of leucine ethyl ester (P/LOEt), or $40 \%$ of tritryptophan (P/WWW), or $40 \%$ of trileucine (P/LLL), respectively.

Through passage through $0.2 \mu \mathrm{m}$ filters solid aggregates were removed without effect on vesicle preparation.

\subsection{Complexes between $P / W W W$ and Liposome Detected} by Size-Exclusion HPLC (SE-HPLC). Phosphatidylcholine/ cholesterol liposome was prepared by the extrusion method as previously reported $[8,14,15]$. Briefly, the mixture of egg yolk phosphatidylcholine $25 \mathrm{mg}$ and cholesterol $6.4 \mathrm{mg}$ (molar ratio, 2:1), dissolved in $\mathrm{CHCl}_{3} / \mathrm{MeOH}(\mathrm{v} / \mathrm{v}, 2: 1$ ), was dried under a stream of nitrogen for $1 \mathrm{~h}$. For hydration, the lipid mixture was hydrated in PBS buffer $1 \mathrm{ml}$ and liposomes were prepared by 15 extrusions through a $0.1 \mu \mathrm{m}$ polycarbonate membrane using a miniextruder (Avanti Polar Lipids, AL, Alabama). Liposome was purified using a Sephadex G-50 (GE Healthcare, Piscataway, NJ, USA) column $(1.5 \times 6 \mathrm{~cm})$.

Liposome $80 \mu \mathrm{L}(2.5 \mathrm{mg} / \mathrm{mL})$ was mixed with varied amount of P/WWW and P/LOEt in $0,10,20$, and $40 \mu \mathrm{L}$ $(2.5 \mathrm{mg} / \mathrm{mL})$ in PBS with final volume adjusted to $200 \mu \mathrm{L}$ with PBS. Samples of $20 \mu \mathrm{L}$ of the mixture were injected for SEHPLC on PolySepGFC-P 4000 (Phenomenex, Torrance, CA, USA) using PBS as a running buffer.

2.6. Transmission Electron Microscopy. The vesicle prepared by liposome complexation with $\mathrm{P} / \mathrm{WWW}$ (ratio 2:1) was kept at room temperature for $30 \mathrm{~min}$. It was then diluted to $1 \mu \mathrm{g} / \mathrm{mL}$ (concentration of Egg PC) with PBS. The nanoparticle was used for TEM analysis without further purification. Briefly, copper grids (300 mesh) coated with carbon (CF300CU, Electron Microscopy Sciences, Fisher Scientific, Pittsburgh, PA) were inverted, carbon surface down, onto $8 \mu \mathrm{L}$ droplets of sample solutions placed on Parafilm. After $5 \mathrm{~min}$, excess liquid was wicked off and the grids were placed onto individual droplets of PBS for 2 minutes. After wiping out excess PBS by Whatman filter paper, grids were placed on aqueous $2 \%$ phosphotungstic acid at $\mathrm{pH}$ 7.0. After $2 \mathrm{~min}$, excess stain was removed and the grids were allowed to dry overnight under vacuum in a desiccator. Images were taken on a JEM 100CX II electron microscope (JEOL USA, Huntington Beach, CA) at $80 \mathrm{kV}$ and collected using an AMT CCD camera (AMT Imaging Software, Woburn, MA).

\subsection{Binding of $P / W W W$ to Giant Unilamellar Vesicles Followed} by Confocal Microscopy. Giant unilamellar vesicles (GUVs) were prepared by the evaporation method $[8,26]$. The GUVs have the same lipid composition as the liposomes (Egg PC) for the leakage assay with additional 1\% (molar) green fluorescent L- $\alpha$-phosphatidylethanolamine-N-(4-nitrobenzo-2oxa-1,3-diazole) (NBD-PE). 


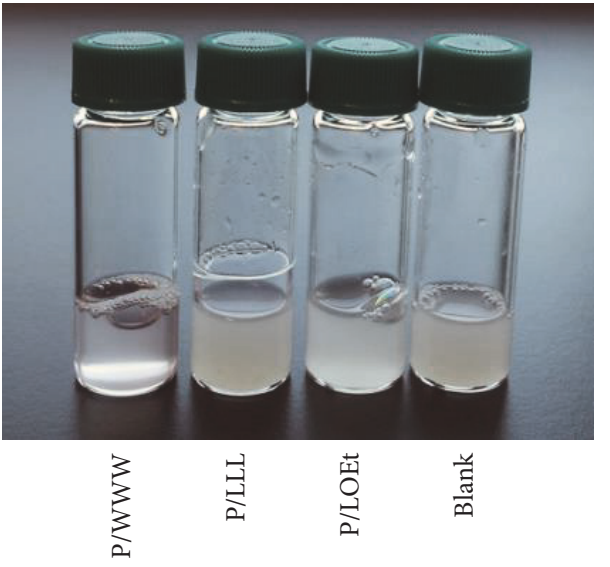

(a)

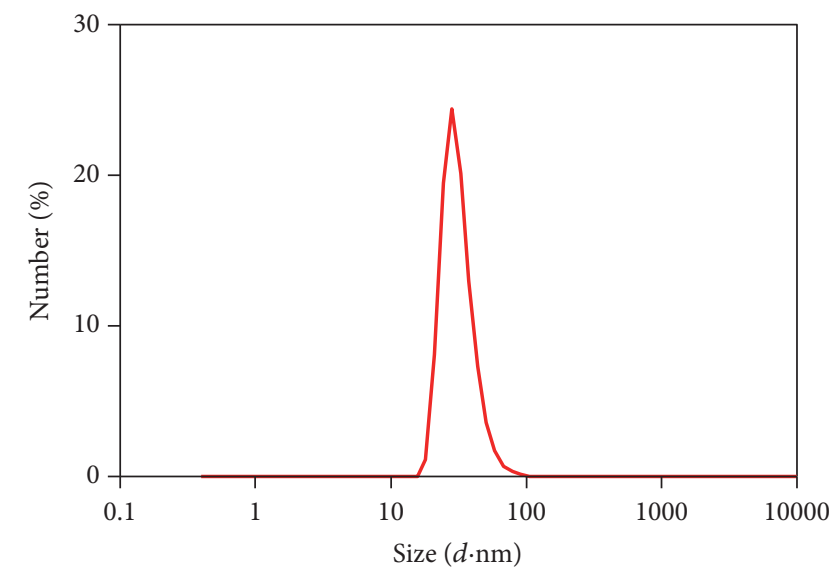

(b)

FIgURE 2: Solubilization of lipid by PMLA copolymers. (a) After preparative separation from large aggregates through $0.2 \mu \mathrm{m}$ pore size filters, multilamellar vesicle (MLV) of Egg PC (L- $\alpha$-phosphatidylcholine) was incubated with the PMLA copolymers (vials from left to right, P/WWW, P/LLL, P/LOEt, and MLV only). The suspensions were then agitated by vortex and sonication under identical conditions. All vials remained turbid except for the added P/WWW (liposome/copolymer weight ratio, 2:1). (b) The hydrophobic diameter of the particles formed in the clear mixture of $\mathrm{P} / \mathrm{WWW}$ and membrane was $33 \pm 1.5 \mathrm{~nm}$ by dynamic light scattering.

For confocal microscopy, the GUVs were incubated with $20 \mu \mathrm{g} / \mathrm{mL}$ of rhodamine labeled P/WWW/Rh in PBS for $30 \mathrm{~min}$ at room temperature (GUV/copolymer weight ratio, $8: 1$ ). A TCS SP $5 \times$ spectral scanner (Leica Microsystems) was used with spectral settings: for NBD, excitation $490 \mathrm{~nm}$ and emission 505-546 nm and for rhodamine, excitation $552 \mathrm{~nm}$ and emission $563-626 \mathrm{~nm}$.

2.8. Fluorescence Resonance Energy Transfer (FRET). Liposome containing $1 \%$ NBD-PE was prepared using extrusion method $[8,15]$ as previously described $(50 \mu \mathrm{g} / \mathrm{mL})$ and was incubated with different concentration of rhodamine$\mathrm{P} / \mathrm{WWW}$ and rhodamine-P/LOEt, $0,0.1,0.2$, and $0.4 \mu \mathrm{M}$ in PBS (concentration of rhodamine) for $30 \mathrm{~min}$. The fluorescence intensity of the mixture was recorded from wavelength $500-620 \mathrm{~nm}$ (excitation wavelength of $460 \mathrm{~nm}$ ) on SPECTRAmax M2 (Molecular Devices) using the SoftMax Pro 5.4.1.

\section{Results}

3.1. Solubilization of Lipid by $P / W W W$. Previously we reported induction of liposome leakage at $\mathrm{pH} 5.0$ and/or $\mathrm{pH} 7.4$ for the copolymers P/LLL, P/LOEt, P/LWL, and $\mathrm{P} / \mathrm{WWW}$ [14]. We identified the mechanisms for membrane permeation of P/LLL and P/LOEt following two distinct mechanisms: "barrel stave" and "carpet" [15]. The interaction between P/WWW and lipid membrane, however, appeared to be different in many ways.

The experimental conditions used here resemble those of previous investigations to allow comparison with the membrane effects of P/LLL and P/LOEt and other PMLA based copolymers $[14,15]$. P/WWW is different by the unique capability to solubilize lipid multilamellar vesicles (MLV) of Egg PC. Before the addition of copolymers, the MLV suspension appeared turbid and opaque (Figure 2(a), blank). MLV treated with P/LLL and P/LOEt remained to be turbid and opaque (Figure 2(a)). In contrast, the lipid suspension treated with $\mathrm{P} / \mathrm{WWW}$ became clear and almost transparent (Figure 2(a)) suggesting that $\mathrm{P} / \mathrm{WWW}$ was able to solubilize lipid membrane by forming soluble complexes. Such soluble complexes were not evident after treatment with P/LOEt and P/LLL.

For further analysis, the solubilized P/WWW-lipid mixture was centrifuged at $5000 \mathrm{rpm}$ for $5 \mathrm{~min}$ and passed through a $0.2 \mu \mathrm{m}$ filter to remove insoluble aggregates. By dynamic light scattering the pass-through contained particles with a hydrodynamic diameter of $33 \mathrm{~nm}$ (Figure 2(b)) which was referred to as the formed $\mathrm{P} / \mathrm{WWW}$-lipid complex. The lipid mixture with P/LOEt and P/LLL was processed in the same way, but particles of any size could not be detected after filtration. This confirms that exclusively P/WWW was able to solubilize the membrane by the formation of copolymerlipids complexes.

\subsection{Analysis of Particles from $P / W W W$ Liposome Mixtures} by Size-Exclusion HPLC (SE-HPLC). We further analyzed whether the solubilization of liposome and the formation of nanoparticles depended on the concentration ratio liposome to P/WWW. The treatment with P/LOEt was used as a negative control. Liposomes with an average size of $100 \mathrm{~nm}$ were fabricated by the membrane extrusion method indicated by SE-HPLC analysis and a single peak at 5.1 min retention time was observed for the untreated liposome (Figure 3(a), curve (D)). When the liposome had been treated with P/WWW (liposome: $\mathrm{P} / \mathrm{WWW}$ weight ratio $8: 1$; see Methods), a broad peak at $7 \mathrm{~min}$ retention time appeared while the intensity of the liposome peak (at $5.1 \mathrm{~min}$ ) had decreased slightly 


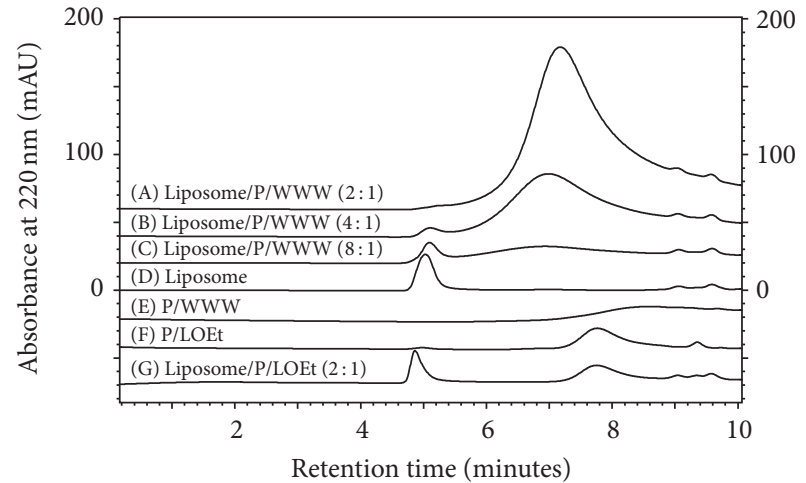

(a)

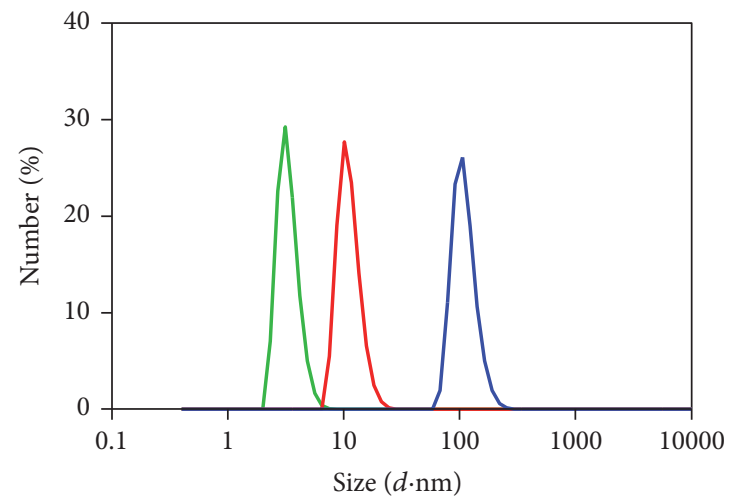

(c)
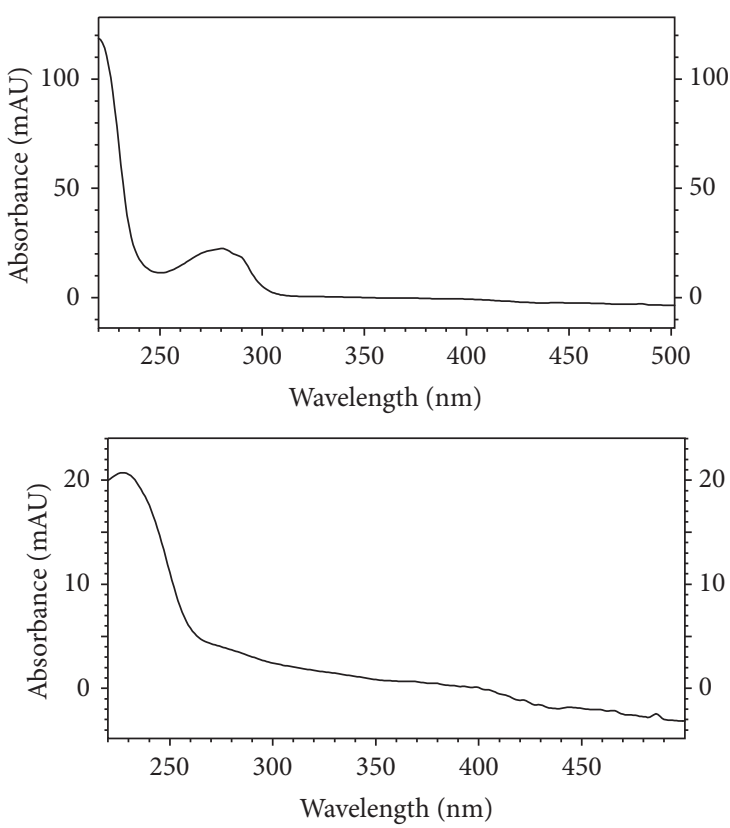

(b)

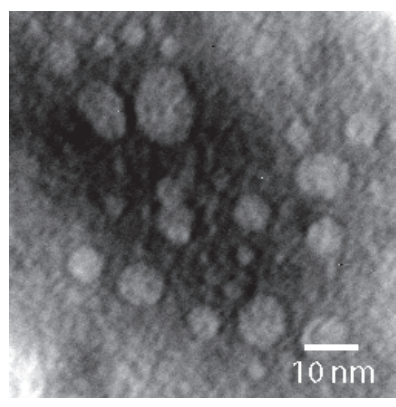

(d)

FIGURE 3: P/WWW liposome particles formed by mixing and physical agitation were analyzed by size-exclusion HPLC (SE-HPLC). (a) SE-HPLC elution profiles of solutions containing liposome, PMLA copolymers P/WWW, or P/LOEt (panel (a), (D)-(F)), and mixtures of liposome and copolymers at different lipid to copolymers molar ratios for liposome/P/WWW (panel (a), (A)-(C)) and liposome/P/LOEt (panel (a), (G)). (b) The UV-vis spectrum of the peak in panel (a) was analyzed by built-in DAD module (diode array detector). Upper spectrum represented the peak in curve (A) (panel (a)) indicated by the characteristic $280 \mathrm{~nm}$ absorbance of tryptophan in liposome/P/WWW complex and the lower spectrum represented the peak of liposome in curve (D). (c) The hydrodynamic diameters of P/WWW (green), liposome (blue), and mixtures P/WWW with liposome (red) were $3.3 \pm 0.2,109 \pm 2.3$, and $10.6 \pm 0.8 \mathrm{~nm}$ by dynamic light scattering. (d) The morphology of the P/WWW liposome particle (same composition as panel (a) liposome/copolymer weight ratio $2: 1$, curve (A)) was analyzed by transmission electron microscopy (TEM). The particle appears to be round in shape and of varying diameter suggesting that the particles derived from liposome/P/WWW were polydisperse with an average size close to $10 \mathrm{~nm}$.

(Figure 3(a), curve $(C)$ ). This trend of a decreasing peak of liposome and formation of a broad peak at 7 min continued at ratios $4: 1$ and $2: 1$ (Figure 3(a), curves $(\mathrm{B})$ and $(\mathrm{A})$ ). At the ratio of $2: 1$, the peak of liposomes at $5.1 \mathrm{~min}$ had almost disappeared, while the complex peak at 7 min was greatly enhanced and slightly shifted to the right (in the direction to the elution of smaller particles). The copolymer P/WWW alone in the same concentration as in the mixture liposomeP/WWW (2:1) showed a broad peak of low intensity and apparent trailing at $8.2 \mathrm{~min}$ retention time (Figure 3(a), curve (E)). This profile (curve (E)) suggested that P/WWW alone strongly adsorbed to the column material resulting in the observed extremely broad distribution extending beyond 10 min elution time.

When P/WWW was complexed with liposome, it became less adsorbed by the SE-HPLC material and the majority of $\mathrm{P} / \mathrm{WWW}$ eluted together with lipids as is noted by the greatly enhanced absorbance at $220 \mathrm{~nm}$ wavelength contributed by 
P/WWW

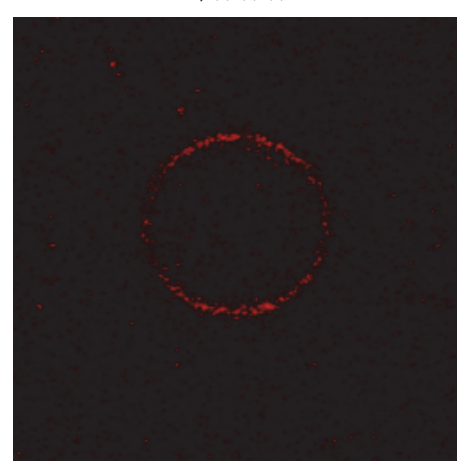

GUV membrane

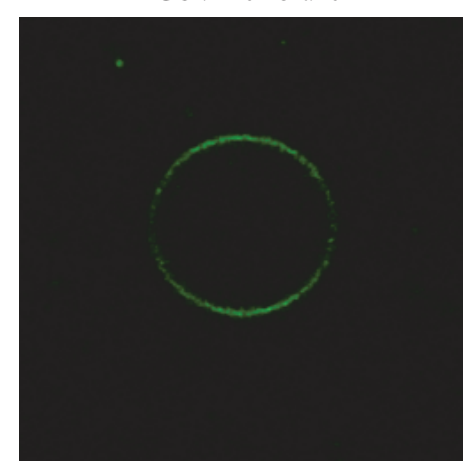

Overlay

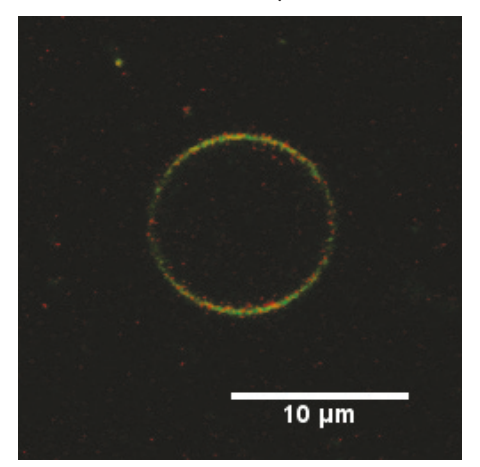

FIGURE 4: Fluorescent confocal microscopy study of binding P/WWW to giant unilamellar vesicle (GUV). P/WWW was labeled with rhodamine (red) and the GUV was labeled with NBD (green) (GUV/copolymer weight ratio 8:1). The fluorescence of P/WWW overlays with that of GUV indicating the binding of P/WWW to the membrane of GUV.

the tryptophan residues (curves $(\mathrm{A})$ and $(\mathrm{B})$ in comparison with free liposome in curve (D) and free P/WWW in curve (E)). The complexation of lipids and P/WWW (the peak of curve (A) in Figure 3(a)) is indicated by the characteristic $280 \mathrm{~nm}$ absorbance of its UV spectrum (Figure 3(b), upper panel), while liposomes alone do not show this (Figure 3(b), lower panel). The broad half-width of peaks in curves (A) and (B) in Figure 3(a) suggests a broad size distribution of nanoparticles also noted by transmission electron microscopy (TEM) in Figure 3(d). In summary, the results in Figure 3 by SE-HPLC, an experiment independent of the lipid solubilization in Figure 2, demonstrate that P/WWW solubilizes liposomes by forming small nanoparticles through complex formation.

In contrast with the effect of P/WWW, the negative control P/LOEt did not show evidence for liposome dissolution as indicated by the fact that P/LOEt (peak $7.8 \mathrm{~min}$, Figure 3(a), curve $(F)$ ) showed no change after mixing with liposome (peak $7.8 \mathrm{~min}$, curve $(\mathrm{G})$ ). A slight shift of the liposome peak from $5.1 \mathrm{~min}$ to $4.9 \mathrm{~min}$ was noticed (curve $(\mathrm{G})$ ). This could be the result of the binding of P/LOEt by liposomes which would give rise to a slight increase in size [15]. However the majority of P/LOEt was not complexed with liposome and there was no additional peak forming at $7 \mathrm{~min}$ as $\mathrm{P} / \mathrm{WWW}$ did. Therefore, even though $\mathrm{P} / \mathrm{LOEt}$ was able to bind to liposome, it was not able to induce solubilization.

For further characterization, the hydrodynamic diameters were measured by dynamic light scattering. The diameters for liposome, P/WWW, and the liposome-P/WWW complex, at a weight ratio liposome: $\mathrm{P} / \mathrm{WWW}$ of $2: 1$, were $109 \pm 2.3,3.3 \pm 0.2$, and $10.6 \pm 0.8 \mathrm{~nm}$ (Figure 3(c)). P/WWW alone indicated an apparent hydrodynamic diameter less than the apparent diameter of $4.5 \mathrm{~nm}$ reported for free polymalic acid of molecular weight $50 \mathrm{kDa}$ [27]. In $\mathrm{P} / \mathrm{WWW}$ the tritryptophan residues are statistically distributed over the length of the polymer platform (PMLA). Moreover, the tripeptide moieties contain a terminal carboxylate. Because of this and because of the experimental finding $\mathrm{P} / \mathrm{WWW}$ diameter $<$ PMLA diameter, formation of $\mathrm{P} / \mathrm{WWW}$ micelles is considered unlikely. By the similar criteria, the absence of micelle formation is also in agreement with the absence of micelles for P/LLL and P/LOEt. On that basis we consider $\mathrm{P} / \mathrm{WWW}$ as freely dissolved molecules. The diameter of liposome-P/WWW complex was $10.6 \mathrm{~nm}$, less than the one of $33 \mathrm{~nm}$ diameter in Figure 2, and refers to different experimental conditions as well as concentration ratios.

The morphology of the liposome derived P/WWW complex was visualized by transmission electron microscopy (TEM). In Figure 2, the median particles show diameters of $10 \mathrm{~nm}$, consistent with the diameter $10.6 \pm 0.8 \mathrm{~nm}$ determined by dynamic light scattering. The size variations of the formed particles are in agreement with the observed broad width of SE-HPLC elution peaks (Figure 3(a), curves (A) and (B)).

\subsection{Confocal Microscopy Study of P/WWW Binding to Lipid} Membrane. SE-HPLC analysis has indicated that P/WWW reacted with liposomes suggesting that $\mathrm{P} / \mathrm{WWW}$ complexed with liposomal membranes before solubilization. Giant unilamellar vesicles (GUVs) of large-sized membranes $(\sim 10 \mu \mathrm{m}$ in diameter) were employed for visualizing the complex formation using confocal microscopy (Figure 4). The concentration of $\mathrm{P} / \mathrm{WWW}(20 \mu \mathrm{g} / \mathrm{mL})$ was low and insufficient to provoke solubilization without agitation. Under this condition, the membrane of GUVs was seen intact as disintegration was not observed. GUVs contained $1 \%$ phosphatidylethanolamine lipid fluorescently labeled with NBD (NBD-PE) at the head groups (Figure 4, middle, in green). $\mathrm{P} / \mathrm{WWW}$ was labeled with rhodamine fluorescence and colocalized with the membrane (in red, Figure 4, left). This suggested that P/WWW had affinity for the liposome lipid membrane to form $\mathrm{P} / \mathrm{WWW}$-lipid complexes. It was considered that this complexation would be on the reaction path to membrane solubilization under condition of high $\mathrm{P} / \mathrm{WWW}$ concentrations (elevated $\mathrm{P} / \mathrm{WWW} /$ liposome ratio, $8: 1$ ). However, previous studies by confocal microscopy of liposomes probed with $\mathrm{P} / \mathrm{LOEt}$ were also seen to bind P/LOEt $[8,15]$, yet $\mathrm{P} / \mathrm{LOEt}$ was not able to solubilize the membrane at any concentration. It is evident from these studies that liposome binding and appropriate concentrations are not 


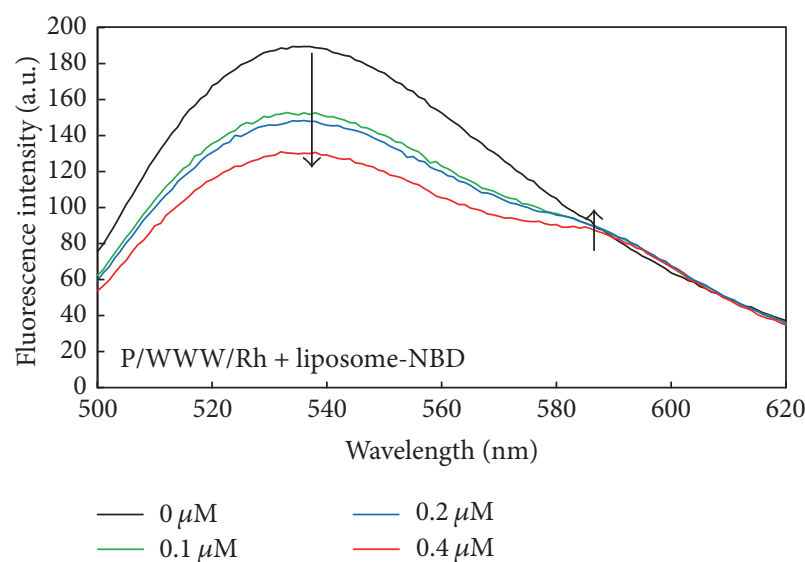

(a)

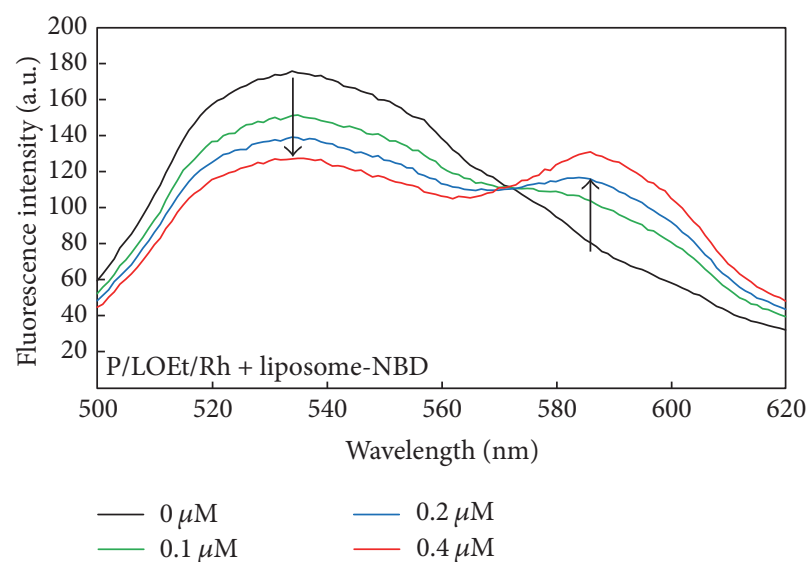

(b)

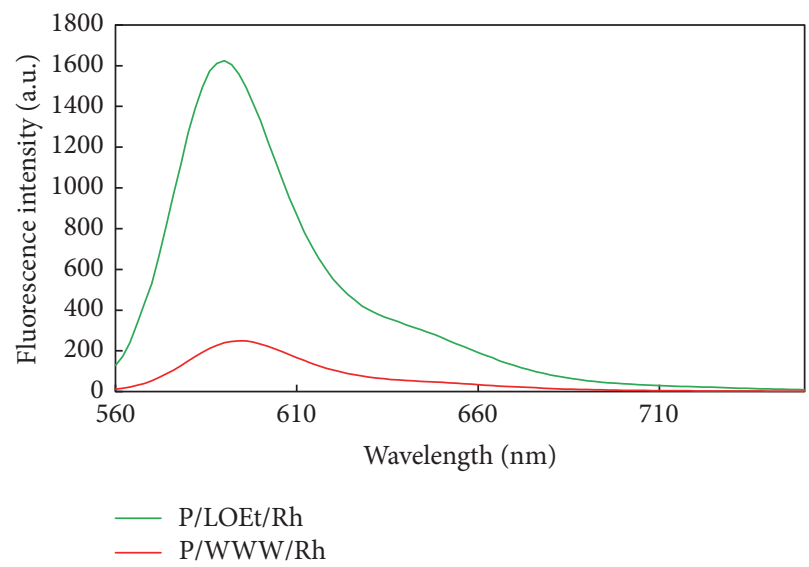

(c)

FIGURE 5: Fluorescence resonance energy transfer (FRET) at pH 7.4 from NBD- phosphatidylethanolamine (NBD-PE) membrane to $\mathrm{P} / \mathrm{WWW} / \mathrm{Rh}$ (a) or P/LOEt/Rh (b). The arrow indicates the increase of FRET with the increase of concentration of P/WWW and P/LOEt/Rh copolymer. (c) The fluorescence emission spectrum of P/WWW/Rh and P/LOEt ranging from $560 \mathrm{~nm}$ to $750 \mathrm{~nm}$ at the same concentration.

the only requirements for membrane solubilization. Metastability of GUV-copolymer particles could be a concern. It has been reported that GUV and SUV (small unilamellar vesicle) may break into smaller mixed micelles after long time incubation with amphiphilic copolymers [28, 29]. However, our measurement of GUV binding with $\mathrm{P} / \mathrm{WWW}$ was not affected by such metastability during our experimental time, but we do not rule out that metastability exists during the binding of P/WWW with GUV.

\subsection{Fluorescence Resonance Energy Transfer (FRET) between} $P / W W W$ and Membrane Lipids. The complexation of $\mathrm{P} /$ WWW with lipid membrane was further studied by FRET. Lipid membranes (Egg PC) contained 1\% phosphatidylethanolamine lipid fluorescently labeled with NBD (NBD$\mathrm{PE}$ ) as the fluorescence donor. Copolymers $\mathrm{P} / \mathrm{WWW} / \mathrm{Rh}$ and $\mathrm{P} / \mathrm{LOEt} / \mathrm{Rh}$ contained rhodamine as the fluorescence acceptor covalently bound to PMLA backbone. Energy transfer was observed for both copolymers P/LOEt/Rh and P/WWW/Rh indicated by an increase in fluorescence intensity for rhodamine acceptor at $585 \mathrm{~nm}$ and a decrease for donor NBD at $535 \mathrm{~nm}$ at pH 7.4 (Figures 5(a) and 5(b)) measured 30 minutes after mixing. However, the increase in rhodamine emission intensity at $585 \mathrm{~nm}$ by $\mathrm{P} / \mathrm{WWW} / \mathrm{Rh}$ was unexpectedly much less (Figure 5(a)) than that of $\mathrm{P} / \mathrm{LOEt} / \mathrm{Rh}$ (Figure 5(b)), on the basis of the similar energy transfer for both copolymers. In fact, at identical concentration the fluorescence of free $\mathrm{P} / \mathrm{WWW} / \mathrm{Rh}$ was only $15 \%$ of the fluorescence for free $\mathrm{P} / \mathrm{LOEt} / \mathrm{Rh}$ in the absence of liposomes (Figure $5(\mathrm{c})$ ) explaining the smaller fluorescence emission increase for $\mathrm{P} / \mathrm{WWW} / \mathrm{Rh}$ in the FRET experiment Figure 5(a). After accounting for this difference, the FRET has occurred similarly for liposome/P/WWW and liposome/P/LOEt. In summary, these experiments confirm complex formation of P/WWW and liposome. We do not rule out that metastability exists during the FRET measurement [30], but such metastability did not affect our FRET measurement.

\section{Discussion}

The lipid membrane of a cell acts as an encapsulating barrier isolating and protecting cellular contents and cell autonomy. Membranes have multiple essential roles managing communication in the context of the embedding organism and in 
the response to incoming signals and their tuning with cellautonomous programs. The lipid composition of a cell reflects its function within the embedding organism. Various types of nature-made molecules have been reported for interactions with lipid membranes including peptides [18, 21, 31], proteins $[32,33]$, and also synthetic polymers [4, 14, 34]. Their varying molecular composition explains different modes and affinities of interactions with the surface and the lipid layer of particular membranes, and their often complex biological properties including binding, membrane permeation, and cellular uptake or escape. Driven by the high interest in the mechanism of pharmacologic functions, peptides, such as antimicrobial peptides [18] and cell penetrating peptides [31], have been studied in detail. Chemical composition, structure, and solvent properties are of interest in this context. More and more water soluble polymers are being used in the formulation of drug carriers and the understanding of the membrane-polymer interaction is essential for their design to be successful. While the chemical composition, structure, and solvent properties of the copolymers contribute to the reactions, membrane composition, tension, fluidity, scrambling, and the tendency for pore are contributing factors. In our investigation, they have not been taken into account while we have focused on the effects of copolymers of polymalic acid, a biodegradable and highly biologically efficient platform of covalent nanodrugs.

The controlled composition and distribution of electrostatically charged, nonpolar, and/or hydrophobic residues have made it possible to synthesize nanocarriers which are responsive to the $\mathrm{pH}$ of the environment. For example, polycations such as positively charged polyethylenimine (PEI) at physiological $\mathrm{pH}$ ( $\mathrm{pH}$ 7.4) bind electrostatically anionic head groups of membranes. The resulting local destabilization and disruption render the lipid layer leaky for the nanocarrier and can be used for cytoplasmic delivery of DNA and siRNA through cellular membranes [35]. However, this method is limited, because the damage is not cell specific and can be rather toxic $[36,37]$. We have chosen a polyanionic polymer, polymalic acid, which is safe, because it does not bind to negatively charged membranes. By the conjugation with hydrophobic amino acid derivatives, typically L-trileucine, Lleucine ethyl ester, and now L-tritryptophan, PMLA acquired the capability for interacting with lipid membranes and was safe and efficient for cytoplasmic delivery of antisense oligonucleotides and other drugs [8-10].

Tryptophan has been found in membrane interactive antimicrobial peptides and cell penetrating peptides [38, 39]. This nonpolar hydrophobic amino acid has a large indole functional group, which by insertion into a hydrophobic lipid bilayer can make strong hydrophobic contacts. Its hydrophilic and hydrophobic attributes make it ideal for its insertion into lipid membranes [40].

On the basis of a liposomal assay to study membrane lysis, we have previously selected the PMLA copolymers $\mathrm{P} / \mathrm{LLL}, \mathrm{P} / \mathrm{LOEt} /$, and P/WWW as typical representatives for efficiently inducing liposome leakage [14]. P/LLL showed $\mathrm{pH}$ sensitive liposome leakage while that for P/LOEt and $\mathrm{P} / \mathrm{WWW}$ was $\mathrm{pH}$ independent ( $\mathrm{pH}$ range 5-7.5). Apparent $\mathrm{pK}_{\mathrm{a}}$ 's of $\mathrm{P} / \mathrm{LLL}$ and $\mathrm{P} / \mathrm{WWW}$ were measured by base titration and found $\mathrm{pK}_{\mathrm{a}}$ (app.) values of 5.5 and 5.8, respectively. The leakage seen for $\mathrm{P} / \mathrm{LLL}$ required that the terminal carboxylate of LLL was neutralized in order to destabilize the membrane [14]. The affinity of the leucyl moieties due to ionization of the terminal carboxylic group at higher $\mathrm{pH}(>6)$ could obviously not compensate for the electrostatic repulsion between terminal carboxylates and the membrane. In the case of $\mathrm{P} / \mathrm{WWW}$, the ionization of the terminal carboxyl group and its hydration did not exclude an apparent interaction with the hydrophobic lipid layer allowing in the $\mathrm{pH}$ range 5-7.5 SE-HPLC (Figure 3). One of the reasons could be that the geometry of the tripeptide allowed at least partial insertion of the indole rings. GUV confocal microscopy (Figure 4) [10] and FRET (Figure 5) are in support of this interpretation, together with previous other results reporting the promotion of peptide uptake by Trp containing peptides [33].

Results of confocal microscopy and FRET experiments (Figure 5) for P/WWW and P/LOEt as well as data published for P/LOEt [15] provide evidence that the copolymers bind to liposome membranes in a similar fashion, which has been described in the case of P/LOEt as the "carpet mode." We hypothesize that at a low copolymer-lipid ratio $\mathrm{P} / \mathrm{WWW}$ also assumes the carpet mode. However, in the case of P/WWW, this mode is unstable and transits to the "belt" mode at higher concentration ratios and physical treatment leading to the formation of the particles $10.6 \mathrm{~nm}$ (Figure 3) and $33 \mathrm{~nm}$ (Figure 2). We hypothesize that the physical background of the transition is explained as follows: the LOEt side chains are electrostatically neutral and penetrate into the lipid layer by virtue of their lipophilicity and the polymer backbone arranges parallel to the membrane surface. In the case of WWW the tryptophan side chains are inserted only partially into the lipid layer, while the charged terminal carboxylate on WWW is excluded and stays on the membrane surface (Figure 6(a)). This carpet configuration is energetically metastable because it interferes with the ordered structure in the lipid layer and provokes electrostatic repulsion between the copolymer carboxylates and the negatively charged head groups at the membrane surface.

The metastable constrained carpet configuration relaxes during physical agitation (stirring and shaking of the reaction mixture) by assuming the "belt-" like configuration. In the "belt" configuration, the terminal carboxylates of WWW and of the polymer orient orthogonally away from the bilayer surface while the indole tryptophan side chains intercalate into the lipid layer (Figure 6(b)). Because the negatively charged groups of $\mathrm{P} / \mathrm{WWW}$ and polymalic acid are now remote from the ionized head groups and the deeper intercalation provides additional hydrophobic binding energy, the new configuration is energetically minimized (Figure 6(c)). We hypothesize that the relaxation from the strained configuration on the membrane surface into the energy favored belt configuration provides the driving force for the translocation.

Even though P/WWW exhibited the capability for solubilizing lipid membranes, this reaction occurred only under vortexing and sonication. Under nonagitating condition, "belt" formation is latent or becomes only slowly established. The transition to belt formation leading to solubilization would depend on membrane fluidity and thus on membrane 


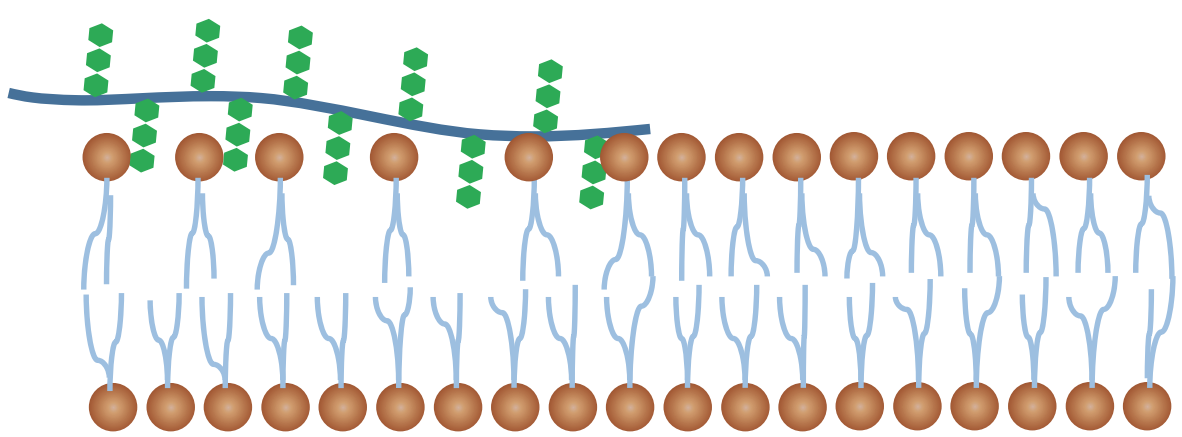

(a)

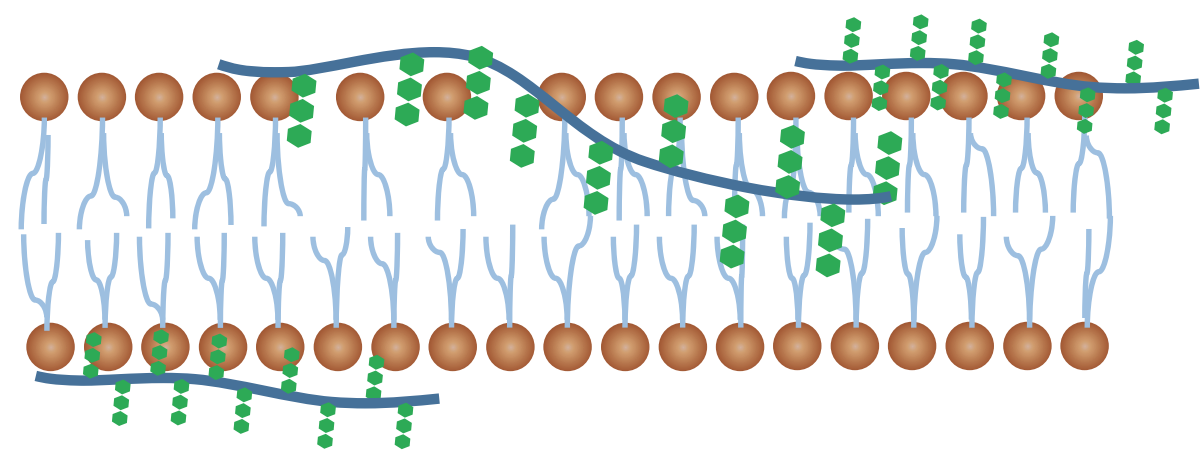

(b)
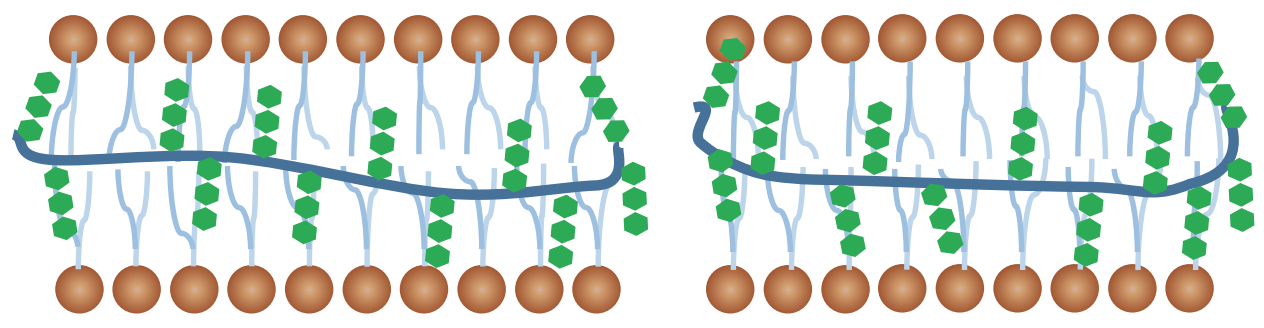

(c)

Figure 6: Hypothetic process of membrane solubilization by P/WWW in three steps. (a) P/WWW molecules first bind to lipid membrane in a carpet-like mode with strong affinity of the tryptophan side chains to the lipid layer. However, the carboxylates of the copolymer interact unfavorably with the charged lipid head group of the outer bilayer surface. (b) Under physical agitation, the latent instability induces a reorganization of the primary P/WWW-lipid complex whereby the copolymer chain starts to move into positions where the carboxylate groups locate between the two layers of charged head groups thereby minimizing the free energy. (c) The transition into the new configuration involves the cooperation of several P/WWW chains and the physical agitation. Multiple P/WWW molecules assume a finally stable configuration in which several polymer molecules constitute belts around single lipid packages. The packages are detached from the original membrane in a process observed as the dissolution of the membrane.

composition and elevated temperature. The "belt" type mechanism of membrane dissolution is based on an alternating distribution of hydrophobic and hydrophilic groups along a polymer which is sufficiently long to form a belt around a raft of lipids. The discussed mode of membrane solubilization is different from the well-established solubilization of liposomes by detergents, because detergents typically have only a few molecular regions of high lipophilicity and hydrophilicity, and they have the spatial molecular adaptability to form mixed micelles with lipids [41, 42]. Moreover, detergents generally are of low molecular mass (small molecular size) and do not have the size to span a lipid raft to form a belt.

Although our model may not take into account the full complexity of possible multiple contributions such as molecular mechanisms of penetration, translocation, pore opening, and stability of dispersed interfaces, it provides a useful working hypothesis. Copolymers with a belt forming capability could offer new pharmaceutical applications. When cancer cells were incubated with P/WWW, we did not notice a disintegration of cell membranes. Only mild toxicity 
was observed at a high concentration of P/WWW $(2 \mathrm{mg} / \mathrm{mL})$ [14]. Nevertheless spontaneously P/WWW induced membrane damage on the pathway of solubilization could occur with anomalous or specialized membranes of extreme composition and membrane fluidity and/or under particular conditions such as hyperthermic treatment of cancer [43].

While P/WWW could be valuable to target and disintegrate malignant cells with the indication of high membrane fluidity, for application in cytoplasmic drug delivery, it remains to be shown whether a direct membranolytic pathway into the cytoplasm is manageable selectively for malignant cells typically having high membrane fluidity, thus favorable over endosome delivery.

\section{Conclusion}

In this work we demonstrated a membrane interacting mode which is unique for copolymer $\mathrm{P} / \mathrm{WWW}$ as distinct from the interaction of copolymers P/LLL and P/LOEt previously termed "barrel stave" and "carpet" modes of membrane interaction. P/WWW and membrane initially form carpetlike complexes, but these are instable and transform under mechanical agitation into stable and soluble belt-like complexes. The overall mechanism is distinctly different from the mechanisms of P/LLL and P/LOEt and also different from liposome dissolution by detergents. We consider the belt forming mechanism by $\mathrm{P} / \mathrm{WWW}$ to be the most invasive one leading to dissolution under conditions of high membrane fluidity.

\section{Conflicts of Interest}

Keith L. Black, Eggehard Holler, Julia Y. Ljubimova, Hui Ding, and Rameshwar Patil are stockholders of Arrogene, Inc., a startup biotechnology company. Keith L. Black and Julia Y. Ljubimova are cofounders, and Eggehard Holler is director of chemical synthesis of Arrogene, Inc. The company did not finance any of the studies described herein.

\section{Acknowledgments}

This work was supported by grants from NIH (R01 CA206220 and U01 CA151815 to Julia Y. Ljubimova and R01 CA209921 to Eggehard Holler).

\section{References}

[1] B. S. Lee, M. Vert, and E. Holler, Water-Soluble Aliphatic Polyesters: Poly(malic acid)s, Wiley-VCH Verlag Gmbh, Weinheim, Germany, Polyester, 1st edition, 2002.

[2] E. Marie, S. Sagan, S. Cribier, and C. Tribet, "Amphiphilic macromolecules on cell membranes: from protective layers to controlled permeabilization," Journal of Membrane Biology, vol. 247, no. 9-10, pp. 861-881, 2014.

[3] M. Schulz, A. Olubummo, and W. H. Binder, "Beyond the lipidbilayer: interaction of polymers and nanoparticles with membranes," Soft Matter, vol. 8, no. 18, pp. 4849-4864, 2012.

[4] M.-A. Yessine and J.-C. Leroux, "Membrane-destabilizing polyanions: interaction with lipid bilayers and endosomal escape of biomacromolecules," Advanced Drug Delivery Reviews, vol. 56, no. 7, pp. 999-1021, 2004.

[5] K. Seki and D. A. Tirrell, "pH-dependent complexation of poly(acrylic acid) derivatives with phospholipid vesicle membranes," Macromolecules, vol. 17, no. 9, pp. 1692-1698, 1984.

[6] R. Chen, S. Khormaee, M. E. Eccleston, and N. K. H. Slater, "The role of hydrophobic amino acid grafts in the enhancement of membrane-disruptive activity of $\mathrm{pH}$-responsive pseudopeptides," Biomaterials, vol. 30, no. 10, pp. 1954-1961, 2009.

[7] A. E. Felber, M.-H. Dufresne, and J.-C. Leroux, "pH-sensitive vesicles, polymeric micelles, and nanospheres prepared with polycarboxylates," Advanced Drug Delivery Reviews, vol. 64, no. 11, pp. 979-992, 2012.

[8] H. Ding, S. Inoue, A. V. Ljubimov et al., "Inhibition of brain tumor growth by intravenous poly ( $\beta$-L-malic acid) nanobioconjugate with $\mathrm{pH}$-dependent drug release," Proceedings of the National Academy of Sciences of the United States of America, vol. 107, no. 42, pp. 18143-18148, 2010.

[9] S. Inoue, H. Ding, J. Portilla-Arias et al., "Polymalic acidbased nanobiopolymer provides efficient systemic breast cancer treatment by inhibiting both HER2/neu receptor synthesis and activity," Cancer Research, vol. 71, no. 4, pp. 1454-1464, 2011.

[10] H. Ding, G. Helguera, J. A. Rodríguez et al., "Polymalic acid nanobioconjugate for simultaneous immunostimulation and inhibition of tumor growth in HER2/neu-positive breast cancer," Journal of Controlled Release, vol. 171, no. 3, pp. 322-329, 2013.

[11] R. Patil, J. Portilla-Arias, H. Ding et al., “Temozolomide delivery to tumor cells by a multifunctional nano vehicle based on poly( $\beta$-L-malic acid)," Pharmaceutical Research, vol. 27, no. 11, pp. 2317-2329, 2010.

[12] R. Patil, J. Portilla-Arias, H. Ding et al., "Cellular delivery of doxorubicin via $\mathrm{pH}$-controlled hydrazone linkage using multifunctional nano vehicle based on poly( $\beta$-L-malic acid)," International Journal of Molecular Sciences, vol. 13, no. 9, pp. 11681-11693, 2012.

[13] R. Patil, A. V. Ljubimov, P. R. Gangalum et al., "MRI virtual biopsy and treatment of brain metastatic tumors with targeted nanobioconjugates: nanoclinic in the brain," ACS Nano, vol. 9, no. 5, pp. 5594-5608, 2015.

[14] H. Ding, J. Portilla-Arias, R. Patil, K. L. Black, J. Y. Ljubimova, and E. Holler, "The optimization of polymalic acid peptide copolymers for endosomolytic drug delivery," Biomaterials, vol. 32, no. 22, pp. 5269-5278, 2011.

[15] H. Ding, J. Portilla-Arias, R. Patil, K. L. Black, J. Y. Ljubimova, and E. Holler, "Distinct mechanisms of membrane permeation induced by two polymalic acid copolymers," Biomaterials, vol. 34, no. 1, pp. 217-225, 2013.

[16] W. H. Binder, "Polymer-induced transient pores in lipid membranes," Angewandte Chemie-International Edition, vol. 47, no. 17, pp. 3092-3095, 2008.

[17] Y. Shai, "Mechanism of the binding, insertion and destabilization of phospholipid bilayer membranes by $\alpha$-helical antimicrobial and cell non-selective membrane-lytic peptides," Biochimica et Biophysica Acta: Biomembranes, vol. 1462, no. 1-2, pp. 55-70, 1999.

[18] Y. Shai, "Mode of action of membrane active antimicrobial peptides," Biopolymers, vol. 66, no. 4, pp. 236-248, 2002.

[19] L. J. Leman, B. E. Maryanoff, and M. R. Ghadiri, "Molecules that mimic apolipoprotein A-I: potential agents for treating atherosclerosis," Journal of Medicinal Chemistry, vol. 57, no. 6, pp. 2169-2196, 2014. 
[20] D. A. Bricarello, J. T. Smilowitz, A. M. Zivkovic, J. B. German, and A. N. Parikh, "Reconstituted lipoprotein: a versatile class of biologically-inspired nanostructures," ACS Nano, vol. 5, no. 1, pp. 42-57, 2011.

[21] Y. Zhao, T. Imura, L. J. Leman, L. K. Curtiss, B. E. Maryanoff, and M. R. Ghadiri, "Mimicry of high-density lipoprotein: functional peptide-lipid nanoparticles based on multivalent peptide constructs," Journal of the American Chemical Society, vol. 135, no. 36, pp. 13414-13424, 2013.

[22] M. C. Phillips, "Thematic review series: high density lipoprotein structure, function, and metabolism new insights into the determination of hdl structure by apolipoproteins," Journal of Lipid Research, vol. 54, no. 8, pp. 2034-2048, 2013.

[23] J.-L. Popot, "Amphipols, nanodiscs, and fluorinated surfactants: three nonconventional approaches to studying membrane proteins in aqueous solutions," Annual Review of Biochemistry, vol. 79, pp. 737-775, 2010.

[24] M. Jamshad, V. Grimard, I. Idini et al., "Structural analysis of a nanoparticle containing a lipid bilayer used for detergent-free extraction of membrane proteins," Nano Research, vol. 8, no. 3, pp. 774-789, 2015.

[25] B. S. Lee and E. Holler, "Beta-poly(L-malate) production by non-growing microplasmodia of Physarum polycephalum. Effects of metabolic intermediates and inhibitors," FEMS Microbiology Letters, vol. 193, no. 1, pp. 69-74, 2000.

[26] A. Moscho, O. Orwar, D. T. Chiu, B. P. Modi, and R. N. Zare, "Rapid preparation of giant unilamellar vesicles," Proceedings of the National Academy of Sciences of the United States of America, vol. 93, no. 21, pp. 11443-11447, 1996.

[27] J. Y. Ljubimova, J. Portilla-Arias, R. Patil et al., "Toxicity and efficacy evaluation of multiple targeted polymalic acid conjugates for triple-negative breast cancer treatment," Journal of Drug Targeting, vol. 21, no. 10, pp. 956-967, 2013.

[28] C. Ladavière, M. Toustou, T. Gulik-Krzywicki, and C. Tribet, "Slow reorganization of small phosphatidylcholine vesicles upon adsorption of amphiphilic polymers," Journal of Colloid and Interface Science, vol. 241, no. 1, pp. 178-187, 2001.

[29] F. Vial, F. Cousin, L. Bouteiller, and C. Tribet, "Rate of permeabilization of giant vesicles by amphiphilic polyacrylates compared to the adsorption of these polymers onto large vesicles and tethered lipid bilayers," Langmuir, vol. 25, no. 13, pp. 7506-7513, 2009.

[30] F. Vial, S. Rabhi, and C. Tribet, "Association of octyl-modified poly(acrylic acid) onto unilamellar vesicles of lipids and kinetics of vesicle disruption," Langmuir, vol. 21, no. 3, pp. 853-862, 2005.

[31] D. M. Copolovici, K. Langel, E. Eriste, and Ü. Langel, "Cellpenetrating peptides: design, synthesis, and applications," ACS Nano, vol. 8, no. 3, pp. 1972-1994, 2014.

[32] W. S. Davidson, T. Hazlett, W. W. Mantulin, and A. Jonas, "The role of apolipoprotein AI domains in lipid binding," Proceedings of the National Academy of Sciences of the United States of America, vol. 93, no. 24, pp. 13605-13610, 1996.

[33] A. G. Lee, "Lipid-protein interactions in biological membranes: a structural perspective," Biochimica et Biophysica Acta, vol. 1612, no. 1, pp. 1-40, 2003.

[34] N. Morimoto, M. Wakamura, K. Muramatsu et al., "Membrane translocation and organelle-selective delivery steered by polymeric zwitterionic nanospheres," Biomacromolecules, vol. 17, no. 4, pp. 1523-1535, 2016.
[35] T. Xia, M. Kovochich, M. Liong et al., "Polyethyleneimine coating enhances the cellular uptake of mesoporous silica nanoparticles and allows safe delivery of siRNA and DNA constructs," ACS Nano, vol. 3, no. 10, pp. 3273-3286, 2009.

[36] P. Chollet, M. C. Favrot, A. Hurbin, and J.-L. Coll, "Sideeffects of a systemic injection of linear polyethylenimine-DNA complexes," Journal of Gene Medicine, vol. 4, no. 1, pp. 84-91, 2002.

[37] A. N. Uduehi, U. Stammberger, B. Kubisa, M. Gugger, T. A. Buehler, and R. A. Schmid, "Effects of linear polyethylenimine and polyethylenimine/DNA on lung function after airway instillation to rat lungs," Molecular Therapy, vol. 4, no. 1, pp. 52-57, 2001.

[38] N. Shagaghi, E. A. Palombo, A. H. A. Clayton, and M. Bhave, "Archetypal tryptophan-rich antimicrobial peptides: properties and applications," World Journal of Microbiology and Biotechnology, vol. 32, no. 2, article 31, pp. 1-10, 2016.

[39] M.-L. Jobin, M. Blanchet, S. Henry et al., "The role of tryptophans on the cellular uptake and membrane interaction of arginine-rich cell penetrating peptides," Biochimica et Biophysica Acta, vol. 1848, no. 2, pp. 593-602, 2015.

[40] M. B. Strøm, Ø. Rekdal, and J. S. Svendsen, "Antibacterial activity of 15-residue lactoferricin derivatives," Journal of Peptide Research, vol. 56, no. 5, pp. 265-274, 2000.

[41] D. Lichtenberg, H. Ahyayauch, and F. M. Goñi, "Erratum: the mechanism of detergent solubilization of lipid bilayers," Biophysical Journal, vol. 105, no. 4, article 1090, 2013.

[42] D. Lichtenberg, H. Ahyayauch, A. Alonso, and F. M. Goñi, "Detergent solubilization of lipid bilayers: a balance of driving forces," Trends in Biochemical Sciences, vol. 38, no. 2, pp. 85-93, 2013.

[43] B. Csoboz, G. E. Balogh, E. Kusz et al., "Membrane fluidity matters: hyperthermia from the aspects of lipids and membranes," International Journal of Hyperthermia, vol. 29, no. 5, pp. 491499, 2013. 

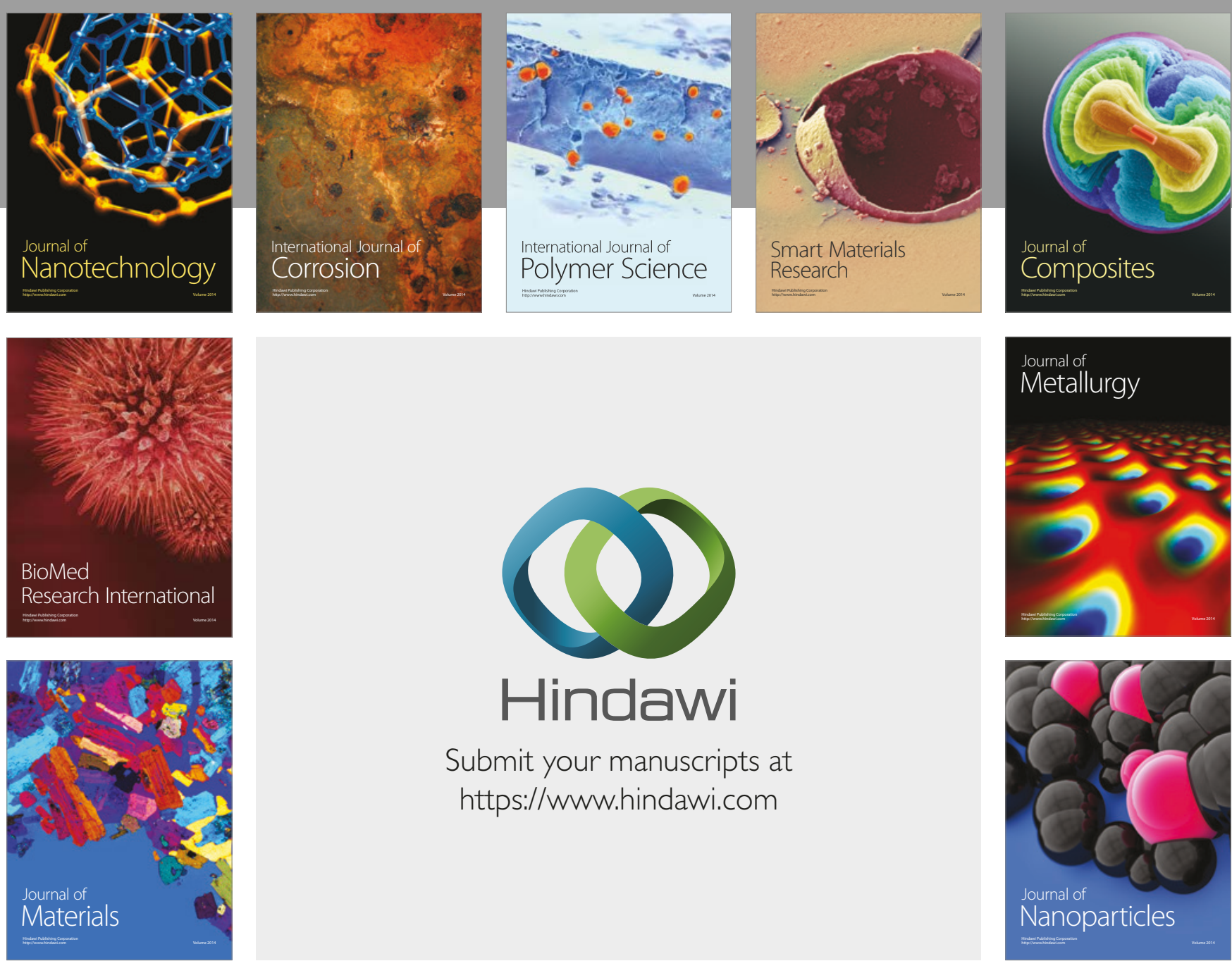

\section{Hindawi}

Submit your manuscripts at

https://www.hindawi.com
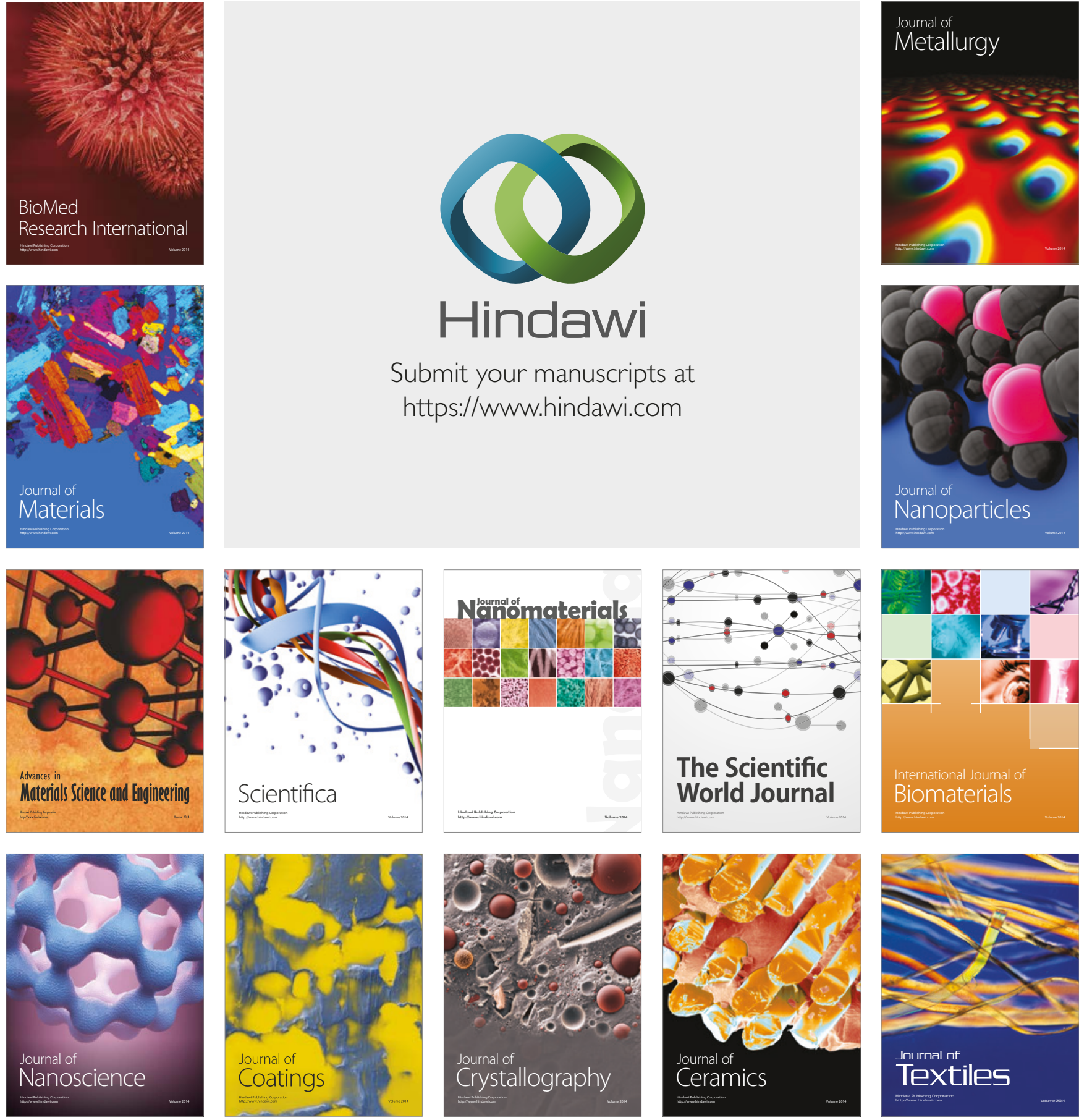

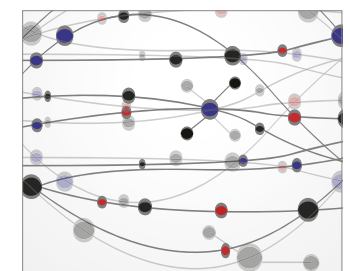

The Scientific World Journal
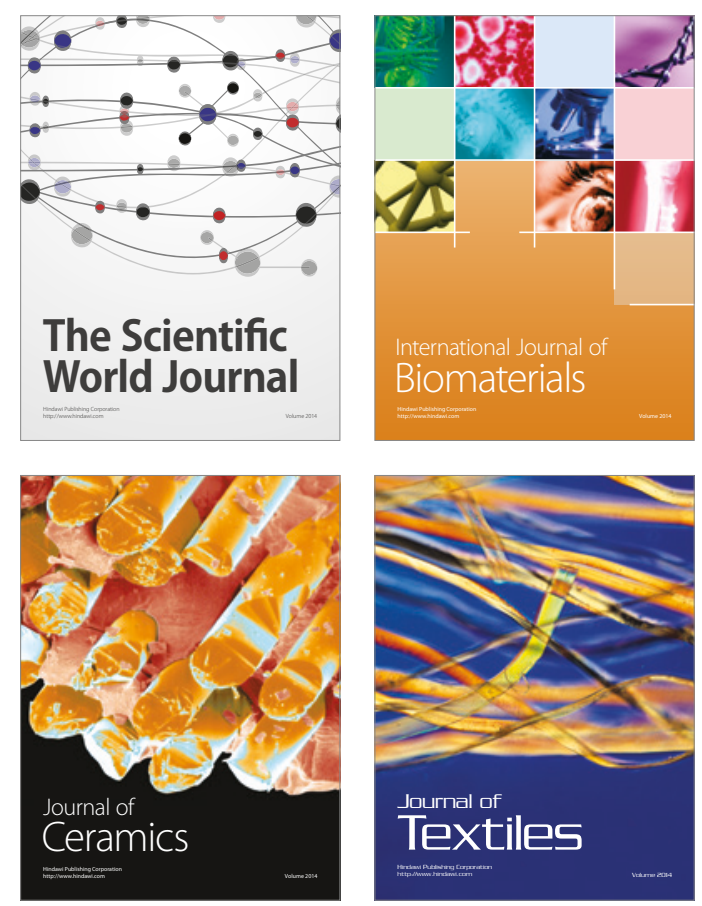